\title{
DESIGN OF A 660V / 15 KVA SINGLE-PHASE UPS BASED ON SERIES CONNECTION OF LOW-OUTPUT-VOLTAGE MODULAR UPS
}

\author{
Telles B. Lazzarin ${ }^{1}$ and Ivo Barbi ${ }^{2}$ \\ ${ }^{1}$ Federal Institute of Santa Catarina (IFSC), Florianópolis - SC, Brazil \\ ${ }^{2}$ Federal University of Santa Catarina (UFSC), Florianópolis - SC, Brazil \\ e-mails: telles@inep.ufsc.br, ivobarbi@inep.ufsc.br
}

\begin{abstract}
Critical loads are usually provided by sources of uninterruptible power supply (UPS). Such devices have output voltages equivalent to levels found in commercial power grids. However, when high output voltages are required there is still no standard solution to achieve the desired level of voltage. This paper proposes the development of a high-output-voltage single-phase UPS based on the series connection of several low-outputvoltage modular UPSs. The main idea is to obtain a commercial UPS in one standard module which can connect several modules in series until reaching the required output voltage. This solution allows high-voltage to be obtained employing only available modules and being of low cost it is suitable for industrial application. In this context, this paper introduces some principles regarding the series connection of UPS, which translates into the serial connection of voltage source inverters (VSIs). Furthermore, the study provides the experimental verification of the proposed system through the development of a prototype of $660 \mathrm{~V}$ and $15 \mathrm{kVA}$, obtained from the connection of three single-phase modules of $220 \mathrm{~V}$ and $5 \mathrm{kVA}$.
\end{abstract}

Keywords - High Output Voltage, UPS, Series Connection.

\section{INTRODUCTION}

In recent years, the demand for solutions based on system integration has attracted the attention of the power electronics community and the electronics industry [1] [2]. This concept has been applied at three levels: component, module and system integration [3] [4]. The parallel connection of uninterruptible power supplies (UPSs), much researched in recent years [5]-[12], and the series connection of UPSs, proposed in this paper, are examples of solutions that are based on the concept of system integration. This tendency to combine simple systems in order to resolve complex problems has resulted from the need for solutions that provide cost reduction, modularity, low maintenance time and reliability.

In this context, the series connection of UPSs, which translates into the series connection of VSIs, is a recent topic which has great potential. This structure was introduced in [4] and has been explored recently in [3] for inverters with input and output stages within a series connection. Recently, this type of connection has also been studied for the connection of Photovoltaic (PV) inverters. The series

Manuscript received 27/01/2012; revised 31/05/2012. Accepted for publication $09 / 07 / 2012$ by recommendation of the Editor Henrique A. C. Braga. connection of UPS was introduced in [26] to obtain an equivalent system of high output voltage and emerges as an attractive option for special applications that require an uninterruptible power supply of medium or high voltage. An advantage of the series connection of UPS is the possibility of employing modular UPSs, as illustrated in Figure 1, which can reduce the cost, designer time and complexity.

A review of the literature reveals that a classic solution to obtain a UPS with an output voltage greater than the voltage provide by the electrical grid employs a standard UPS and a transformer at the output to raise the voltage to the desired value. However, this solution requires a special transformer and a single UPS provides all of the load power. Other solutions reported in the literature are based on three converters: an AC-DC, a DC-DC booster, and a DC-AC. In most cases the differences between the structures are found in the second and third stages. The DC-DC solution was obtained through converter boosters [13] [14] or the series connection of DC-DC converters [15]-[18]. The DC-AC solution has been used for traditional VSIs employing high voltage components [19], or for a multilevel inverter [20][25]. The combination of these options creates interesting solutions. Nevertheless, many of them require control and modulation strategies and also the topologies are patented. Additionally, all options reviewed employ the integration of modules, that is, each specification requires a new design for the internal structure of the UPS.

The series connection of UPSs introduced recently in [26] still has many aspects to be explored. In this context, this paper extends the studies on the series connection of singlephase commercial UPSs to design high-output-voltage UPSs.

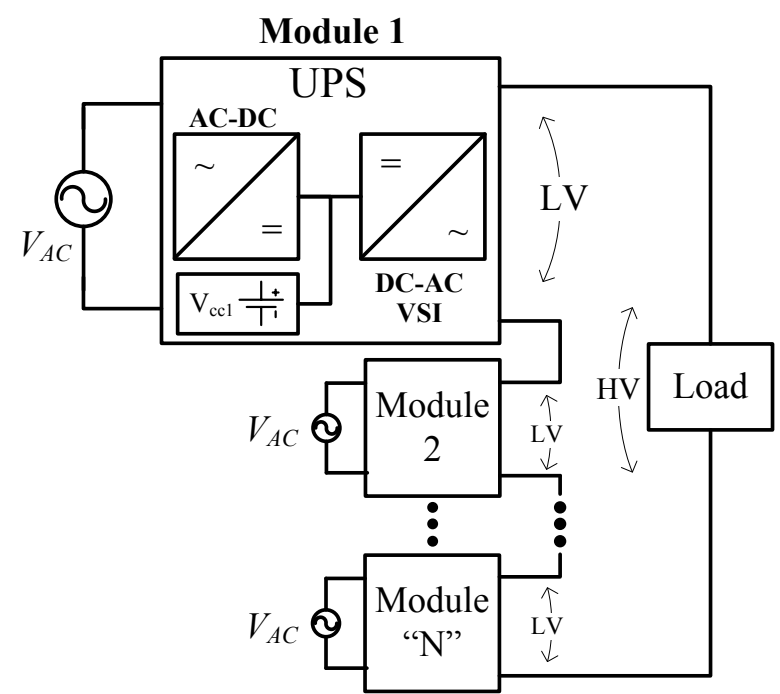

Fig. 1. Topology for high-output-voltage single-phase UPS based on the series connection of low-output-voltage modular UPSs. 


\section{SERIES-CONNECTED SINGLE-PHASE INVERTERS}

The series connection of the inverter proposed in this paper is seen in Figure 2. Each single-phase UPS of low output voltage is called a module. Module 1 shows the structure of the power circuit and the block diagram of the control circuit of a low-output-voltage modular UPS. The modules are independent of each other and each one has a voltage control to regulate its output voltage. This study employs the UPS shown in Module 1 since it is a typical commercial UPS.

A required specification for the modules in Figure 2 is that the isolation voltage between the transformer coils needs to be higher than the total output voltage $\left(V_{o}\right)$.

\section{A. Principle of Operation}

The output voltages of all modules of Figure 2 are connected in series and, therefore, the output voltages of the inverters from the UPSs are directly connected in series. An inverter can be simplified by having one voltage source and thus the series connection behavior of UPSs is similar to the series connection of voltage sources, as exemplified in Figure 3 (a). Voltage sources have the advantage of working naturally in series even if they are of different magnitudes, phases and frequencies. In the specific case of inverters, however, they must not receive active power flow.

On analyzing a small system of two series-connected UPSs, the behavior of each one and the resultant output voltage applied to the load are shown in Figure 3 (b). The active and reactive power flow in the voltage sources $1\left(V_{o 1}\right)$ and $2\left(V_{o 2}\right)$ are defined by (1), (2), (3) and (4), where $V_{o 1}$ and $V_{o 2}$ are the magnitudes and $\phi_{12}$ is the phase between the voltage sources. Figure 3 (c) illustrates the phasors of both voltages.

$$
\begin{gathered}
P_{1}=\frac{V_{1}^{2}+V_{1} \cdot V_{2} \cdot \cos \left(\phi_{12}\right)}{R_{o}} \\
Q_{1}=-\frac{V_{1} \cdot V_{2} \cdot \sin \left(\phi_{12}\right)}{R_{o}} \\
P_{2}=\frac{V_{2}^{2}+V_{1} \cdot V_{2} \cdot \cos \left(\phi_{12}\right)}{R_{o}} \\
Q_{2}=-\frac{V_{1} \cdot V_{2} \cdot \sin \left(\phi_{12}\right)}{R_{o}}
\end{gathered}
$$

Equations (1) to (4) show that if $\phi_{12}$ is null the reactive power flows between the sources are null and all of the active power supplied by the sources is to the load. Therefore, there are no active power flows between the sources. The equations also show that if $\phi_{12}$ is null the relation between the magnitudes determines the active power supplied by each source to the load. These characteristics also apply to other types of load.

Another important consideration is that small variations in the magnitude and phase of the sources do not generate a significant change in their power flows. This is because the active power flow is mainly dependent on the magnitude and the reactive power flow on the phase. This characteristic leaves the system more robust.

The circuit of Figure 2 presents this important characteristic when the voltage references of all UPSs are synchronized, because it is possible to obtain all voltages in phase and with the same magnitude. Consequently, the exchange of power between the inverters is avoided and the power load sharing among the UPSs is proportional to the magnitude of their output voltages. In Figure 2, the synchronism of the reference voltages is carried out through a common bus communication, which provides the $V_{\text {ref }}$ signal for all UPSs connected in series.

Therefore, the resultant $V_{o}$ of the output voltage in Figure 2 is the sum of all the voltages, as seen in (5). In situations of non-load operation, the structure in Figure 2 is an open circuit and has no current circulation. However, under load operation it has the current circuit of Figure 2, which is the same for all of the modules. Therefore, the power supplied to the load is defined by (6), as a function of the $I_{o}$ and output voltage of all modules. Equation (6) shows that the total power of the load is divided among the UPSs, proportionally to their individual voltages. Through (6) it is also possible to demonstrate that the total power of the load is the sum of the power supplied by all UPSs, as defined in (7), (8) and (9).

$$
\begin{gathered}
V_{o}=V_{o 1}+V_{o 2}+\amalg V_{o N} \\
S_{o}=V_{o 1} \cdot I_{o}+V_{o 2} \cdot I_{o}+\amalg V_{o N} \cdot I_{o} \\
S_{o}=S_{o 1}+S_{o 2}+\amalg S_{o N} \\
P_{o}=P_{o 1}+P_{o 2}+\amalg P_{o N} \\
Q_{o}=Q_{o 1}+Q_{o 2}+\amalg Q_{o N}
\end{gathered}
$$

One of the main advantages of the serial connection is that small variations among the output voltages of the inverters do not cause significant imbalances in the power load sharing. Therefore, in the proposal of Figure 2 there is no need to add a new control system to carry out the series connection of the VSIs. The instantaneous voltage control already present in the modular UPSs, with their voltage references synchronized, is sufficient to ensure proper power load sharing among the converters.

\section{B. High-Output-Voltage UPS}

The high-output-voltage UPS proposed in this paper is obtained by summing the output voltages of all low-outputvoltage UPS, as described in (5). In this way, an equivalent UPS of high output voltage is built from "N" UPS of lowoutput voltage. An UPS can be transformed into a standard module and any voltage specification can be achieved with the series connection of "N" standard UPSs. This proposal reduces the designer time and cost and makes use of commercially available structures. The use of modules facilitates the maintenance and the replacement of units.

Another advantage of the series connection of inverters is that the load power is shared among them and thus the inverters can be designed for lower power. Moreover, for UPSs, the series connection distributes the energy backup in smaller battery banks which are present in each module.

An important aspect of the high-output-voltage UPS is the bypass operation mode. As the load voltage is greater than that of the electrical grid, the UPS needs a transformer in the bypass circuit. Another point relates to the situation where one module needs to be disconnected from the system. In this case, the system can either work in bypass mode or a specific control places the inverter output in short circuit and increases the output voltage of other modules. 


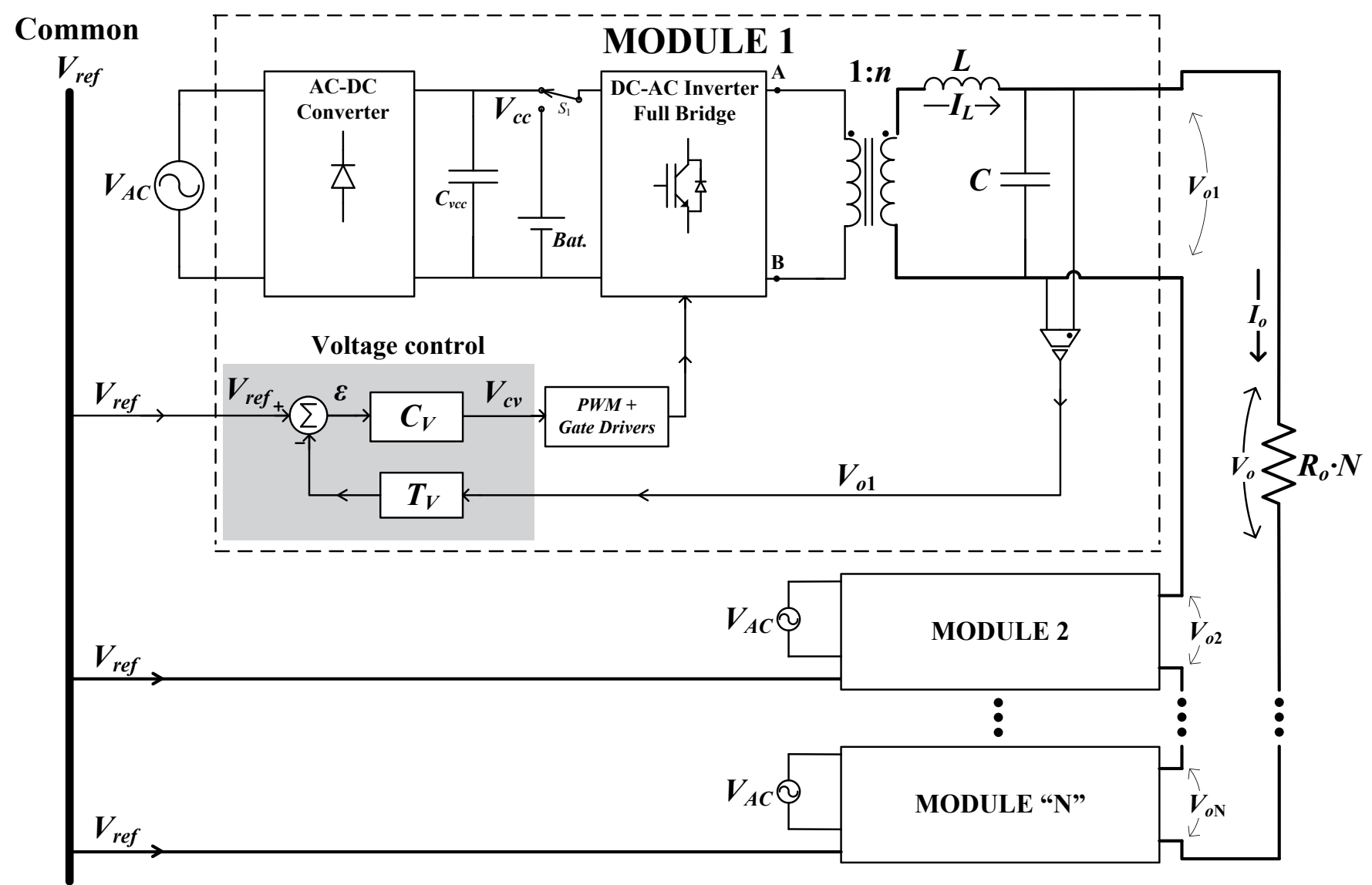

Fig. 2. Proposal for a high-output-voltage single-phase UPS based on the series connection of low-output-voltage modular UPSs.

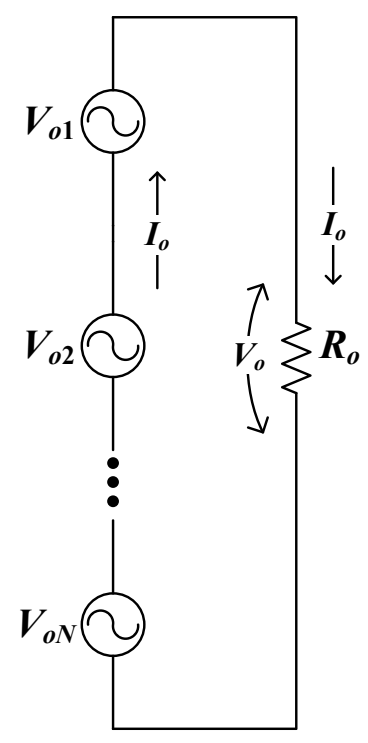

(a)

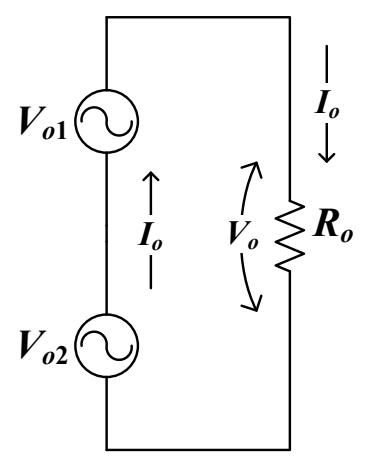

(b)

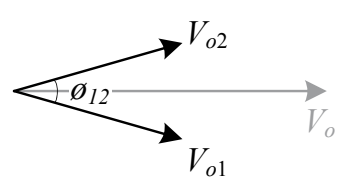

(c)
Fig. 3. (a) Behavior of "N" series-connected inverters; (b) Behavior of two series-connected inverters; and (c) Phasors of output voltages of two series-connected inverters.

\section{Control Strategy of a Modular Single-Phase Inverter}

The modules of the structure in Figure 2 have only the traditional instantaneous voltage control. Module 1 shows in detail the voltage control diagram. Controller $C_{v}$ comprises a proportional-integral-derivative (PID) and a low-pass filter (LPF), as defined in (10). In this equation $z_{1}$ and $z_{2}$ are the zeros, $p_{1}$ is the pole and $K_{c v}$ is the gain of the controller. This control strategy ensures a regulated output voltage at each module, for linear and non-linear loads. In addition, as the voltages of $V_{o 1}$ and $V_{o 2}$ up to $V_{o N}$ are regulated, it is possible to affirm that the resulting voltage $V_{o}$ is also regulated and responds appropriately to linear and non-linear loads.

$$
C_{v}(s)=K_{c v} \cdot \frac{\left(s+z_{1}\right) \cdot\left(s+z_{2}\right)}{\left(s+p_{1}\right) \cdot s}
$$

The structure shown in Module 1 may present problems associated with the dc level in the primary winding of the transformer due to the fact that the voltage sensor is in the secondary winding. There are many ways to solve this problem and one is through a control loop, as proposed in [27] and [28]. However, since the focus of this study is the series connection of the inverter, this point will not be addressed herein.

\section{DYNAMICS ANALYSIS OF THE SERIES- CONNECTED INVERTERS}

This section analyzes the dynamic response of the equivalent structure obtained through the series connection of VSIs. This study seeks to find the simplified circuit of Figure 2, shown in Figure 4 (a), which considered all inverters as equal. 


\section{A. Small-Signal Model}

The small-signal model of the inverter shown in module 1 of Figure 4 (a) is seen in (11) (which is the classic VSI model).

$$
H_{1}=\frac{1}{s^{2} \cdot L \cdot C+s \cdot \frac{L}{R_{o}}+1}
$$

Based on the analysis of the circuit of Figure 4 (a) the equivalent circuit of Figure 4 (b) is found, which represents the equivalent circuit of series-connected inverters. The output impedances from the inverters (LC filters) are all connected in series. Therefore, the equivalent circuit in Figure 4 (b) has an inductance "N" times larger and a capacitance "N" times smaller, where "N" is the number of inverters connected in series. The small-signal model of Figure 4 (b) is shown in (12) and this result is very interesting because $H_{V S I}$ series is equal to the model for one inverter found in (11). Thus, the structure of series-connected inverters has the same dynamic response as one isolated inverter.

$$
H_{V S I_{-} \text {series }}=\frac{1}{s^{2} \cdot L \cdot \not \mathcal{X} \cdot \frac{C}{\not \supset}+s \cdot \frac{L \cdot \grave{X}}{R_{o} \cdot \grave{X}}+1}
$$

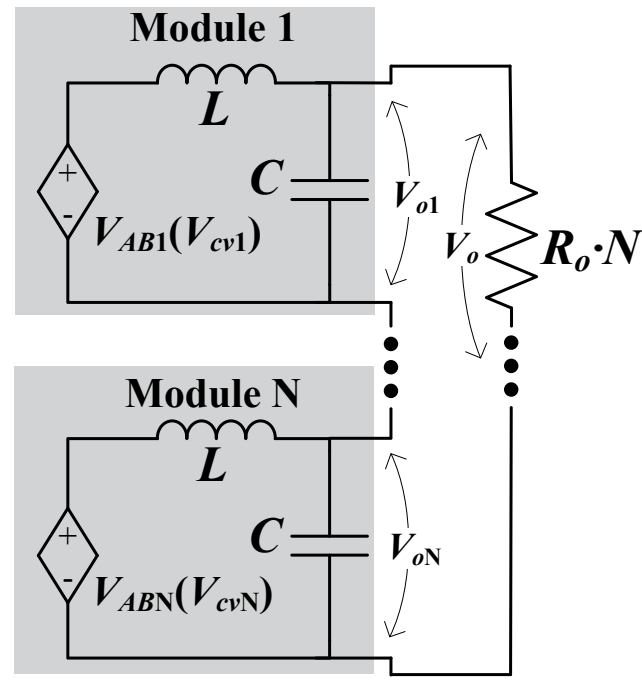

(a)

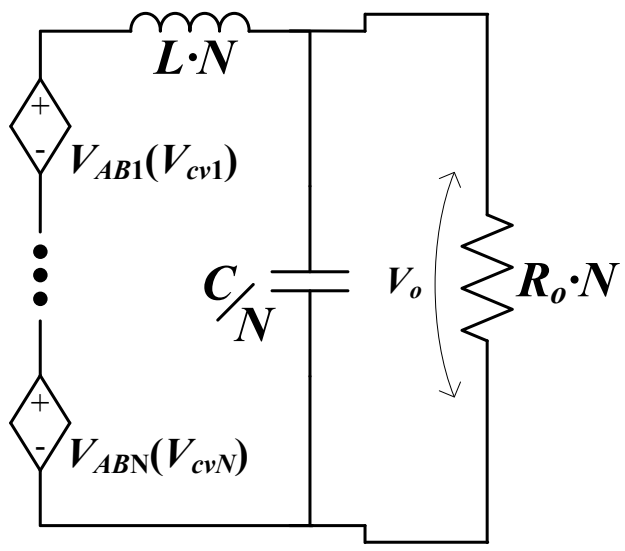

(b)

Fig. 4. Dynamic analysis of the series-connected inverters. (a) Model of "N" inverters. (b) Resulting model for "N" inverters.

\section{B. Dynamic Response}

Equation (13) defines the closed-loop transfer function (CLTF) of "N" inverters as seen in Figure 2. The transfer function (CLTF) of (13) describes the output voltage of each module in relation to the reference voltage. On substituting (13) in (5), (14) is obtained, which describes the CLTF of the "N" inverters connected in series. Thus, equation (14) describes the resulting output voltage, $V_{o}$, as a function of the reference voltage, $V_{\text {ref }}$, common to all inverters.

$$
\begin{gathered}
\frac{V_{o 1}}{V_{r e f}}=\mathrm{CLTF}_{i n v 1} \quad \frac{V_{o 2}}{V_{r e f}}=\mathrm{CLTF}_{i n v 2} \quad \text { 四 } \frac{V_{o N}}{V_{r e f}}=\mathrm{CLTF}_{i n v N} \\
\frac{V_{o}}{V_{r e f}}=\mathrm{CLTF}_{i n v 1}+\mathrm{CLTF}_{i n v 2}+\mathrm{WLTF} \mathrm{CLF}_{i n v N}
\end{gathered}
$$

Figure 5 plots an example of the Bode diagram for the three different structures seen in Figure 2. The first, with one inverter; the second, with two inverters; and the third, with three inverters connected in series. The curves of Figure 5 are drawn with the transfer functions (7) and (8), and they consider that all inverters are equal. The curves of Figure 5, for one, two or three series-connected inverters, have the same frequency band with constant gain, the same resonant frequency and equal damping. The only difference between the curves in Figure 5 is the static gain of $V_{o}$ in relation to $V_{r e f}$, which increases proportional to the number of inverters connected in series. This is to be expected because the output voltage $V_{o}$ increases when more inverters are connected in the system. The Bode phase diagram was also analyzed and presented the same response for the three cases.

\section{IV.SERIES-CONNECTED THREE-PHASE INVERTERS}

The purpose of this section is to extend the principle of series connection to three-phase inverters, with the focus on its application in a three-phase UPS. A possible structure for the three-phase connection is shown in Figure 6. The inverters are isolated through a three-phase transformer and have an LC filter (typical structure used in UPS). The secondary coils of transformers are not connected to each other and thus the series connection of the inverters is possible.

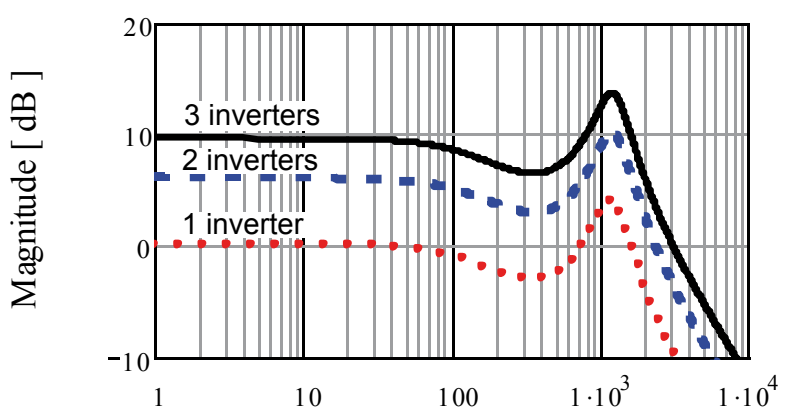

$[\mathrm{Hz}]$

Fig. 5. Bode magnitude diagram of one, two and three inverters connected in series. 


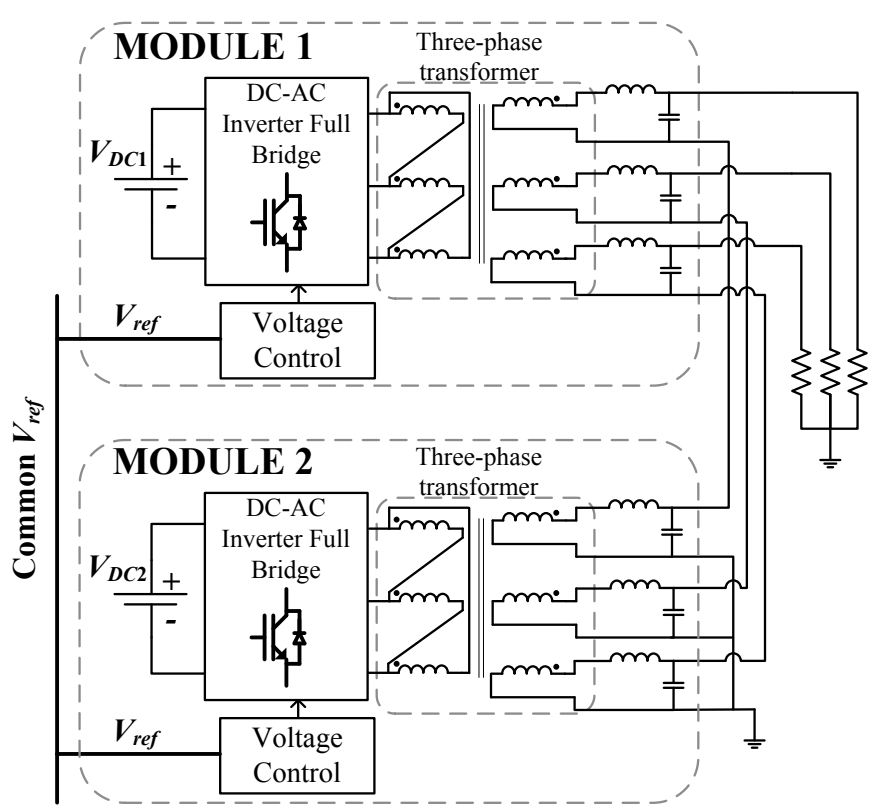

Fig. 6. Proposal for a high-output-voltage three-phase UPS based on the series connection of three-phase inverters.

\section{EXPERIMENTAL RESULTS}

In order to verify the proposal of this paper a prototype with three $5 \mathrm{kVA}$ UPSs connected in series was built. The structure tested can be seen in Figure 2, the photograph in Figure 7 shows the prototype with modules 1,2 and 3 and Table I provides the main specifications for the design. The switching frequency was $10 \mathrm{kHz}$ in all VSIs.

The prototype with three series-connected inverters provides an output voltage $V_{o}$ of $660 \mathrm{~V}_{\text {rms }}\left(3 \times 220 \mathrm{~V}_{\mathrm{rms}}\right)$, which corresponds to a peak voltage of $933 \mathrm{~V}_{\text {peak }}$. It was tested under non-load and under resistive, inductive and nonlinear loads. The results are shown in the waveforms of Figures 8 to 15 . These figures display the total output voltage $\left(V_{o}\right)$, the voltages in the modules $1\left(V_{o 1}\right), 2\left(V_{o 2}\right)$ and $3\left(V_{o 3}\right)$ and the load current $\left(I_{o}\right)$.

Figure 8 presents the results for the test carried out under non-load conditions. The measured values for $V_{o 1}, V_{o 2}, V_{o 3}$ and $V_{o}$ were $220 \mathrm{~V}, 219 \mathrm{~V}, 221 \mathrm{~V}$ and $660 \mathrm{~V}$, respectively. The waveforms represent $1 \%$ of the total harmonic distortion (THD). These results demonstrate that the proposed connection functions properly and thus the desired output voltage of the series connection of three UPSs is obtained.

The results for the test carried out under resistive load can be seen in Figures 9 and 10. The voltages $V_{o 1}, V_{o 2}, V_{o 3}$ and $V_{o}$ are shown in Figure 9 and their measured values were $214 \mathrm{~V}$, $214 \mathrm{~V}, 215 \mathrm{~V}$ and $643 \mathrm{~V}$, respectively. The measured THD of these waveforms were $2.6 \%$. The static regulation was $3 \%$. The power load supplied is $13.18 \mathrm{~kW}$ and the resistive load current $\left(I_{o}\right)$ is shown in Figure 10 together with $V_{o 1}, V_{o 2}$ and $V_{o}$. The results show that it is possible to correctly regulate the output voltage $V_{o}$ through the individual control of each UPS, in other words, by controlling the voltages $V_{o 1}$, $V_{o 2}$ and $V_{o 3}$.

The test results obtained under an inductive load of $9.45 \mathrm{kVA}$ and power factor of 0.62 are shown in Figures 11 and 12. The voltages $V_{o 1}, V_{o 2}, V_{o 3}$ and $V_{o}$ are given in Figure 11 and their measured values were $222 \mathrm{~V}, 223 \mathrm{~V}$,

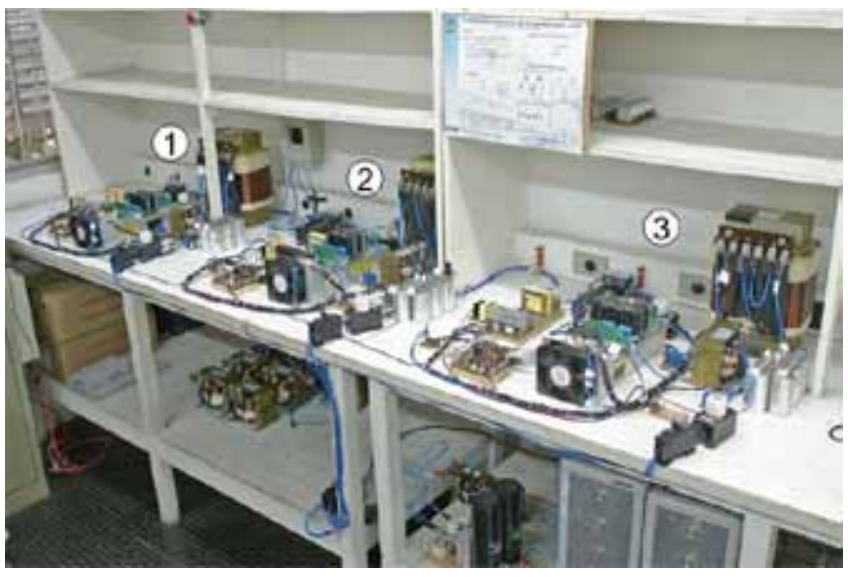

Fig. 7. Photograph of the prototype with three $5 \mathrm{kVA}$ inverters (modules) connected in series.

TABLE I

Design Specifications

\begin{tabular}{lll}
\hline$V_{A C}=220 \mathrm{~V}_{\mathrm{rms}}$ & $T_{V}=0.016$ & $V_{o 1} / V_{o 2} / V_{o 3}=220 \mathrm{~V}_{\mathrm{rms}}$ \\
\hline$n=1.63$ & $K_{C_{V}}=14.7$ & $S_{o 1} / S_{o 2} / S_{o 3}=5 \mathrm{kVA}$ \\
\hline$L=1100 \mu \mathrm{H}$ & $z_{1}=888 \mathrm{~Hz}$ & $\mathrm{~N}=3$ \\
\hline$C=36 \mu \mathrm{F}$ & $z_{2}=328 \mathrm{~Hz}$ & $V_{o}=660 \mathrm{~V}_{\mathrm{rms}}$ \\
\hline$V_{\text {ref }}=5 \mathrm{~V}$ (peak) & $p_{1}=34050 \mathrm{~Hz}$ & $S_{o}=15 \mathrm{kVA}$ \\
\hline
\end{tabular}

$223 \mathrm{~V}$ and $668 \mathrm{~V}$, respectively. The inductive load current $\left(I_{o}\right)$ is given in Figure 12 and its value is $14 \mathrm{~A}$. This figure also displays the voltages $V_{o 1}, V_{o 2}$ and $V_{o}$. It can be seen that the load current is not in phase in relation to $V_{o 1}, V_{o 2}, V_{o 3}$ and $V_{o}$, however, both voltages are still in phase and properly regulated.

Figures 13 and 14 show the test under a non-linear load of $8.3 \mathrm{kVA}$ and with a crest factor of 2.5. The voltages $V_{o 1}, V_{o 2}$, $V_{o 3}$ and $V_{o}$ are shown in Figure 13 and their measured values were $216 \mathrm{~V}, 217 \mathrm{~V}, 217 \mathrm{~V}$ and $650 \mathrm{~V}$ while the THD values were $3.2 \%, 3.2 \%, 3.0 \%$ and $3.1 \%$, respectively. The value for the load current $\left(I_{o}\right)$ is $12.7 \mathrm{~A}$ (32 A peak) and it can be seen in Figure 14 that this also presents $V_{o 1}, V_{o 2}$ and $V_{o}$. It can be noted that the system regulates $V_{o}$ properly, even for this type of load.

A dynamic test was also performed, in which one step of 0 to $50 \%$ load (resistive) was applied. Figure 15 shows the voltages $V_{o 1}, V_{o 2}$ and $V_{o}$ and load current $I_{o}$ during the test. The output voltage $V_{o}$ has the same dynamic response as the voltages $V_{o 1}$ and $V_{o 2}$, verifying the theoretical study. Moreover, the transient voltage response is smooth, demonstrating the robustness of the system.

\section{CONCLUSIONS}

This paper proposed a simple solution to building a highoutput-voltage UPS based on the series connection of inverters. The theoretical study demonstrated that the equivalent UPS maintains the dynamic characteristics and total output voltage of the inverters. Moreover, the loadpower is shared naturally among all inverters, without the need to introduce new control strategies. Thus, it is possible to carry out the series connection of low-output-voltage, modular, commercially available and low cost UPSs, and thereby obtain an equivalent UPS of high output voltage. 
The experimental results obtained for a $15 \mathrm{kVA}$ prototype verified the principles of this proposal. Furthermore, this strategy is also attractive for other applications, at low and high voltages. One example of where the principle of series connection in UPS could be applied is the Brazilian market. A manufacturer could have a standard UPS designed for an output-voltage of $127 \mathrm{~V}$ and then use two UPS in series connection to attend regions where the electrical grid is $220 \mathrm{~V}$.

The series connection of inverters is a recent research topic and there are still many aspects to be addressed in future studies. These include a control system that allows the connection and disconnection of the inverters and compensates the output voltage acting on the other inverters, new options for bypass operation when the load voltage is not the same as the electrical grid voltage and a study on modulation strategies for inverters.

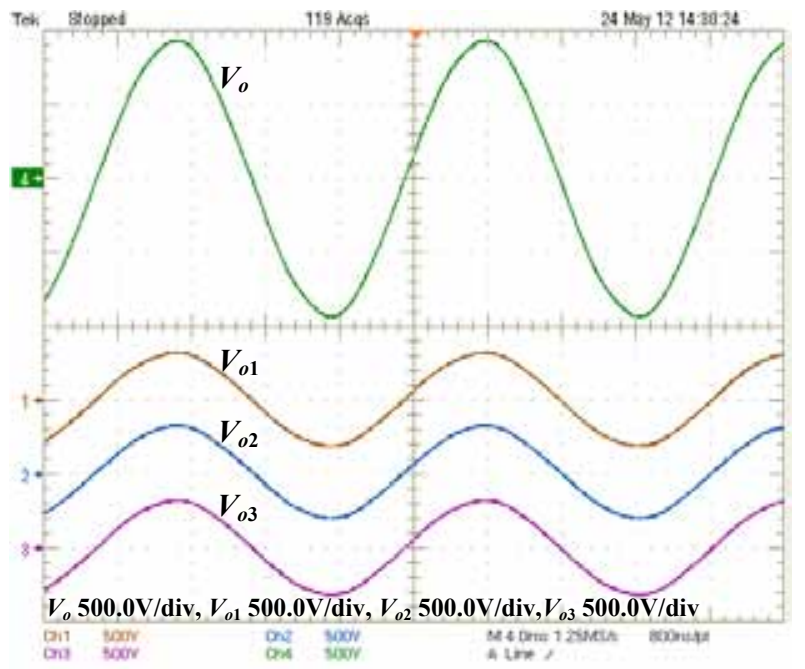

Fig. 8. Experimental results under non-load operation. Outputvoltages of the UPS $\left(V_{o}\right)$, module $1\left(V_{o 1}\right)$, module $2\left(V_{o 2}\right)$ and module $3\left(V_{o 3}\right)$.

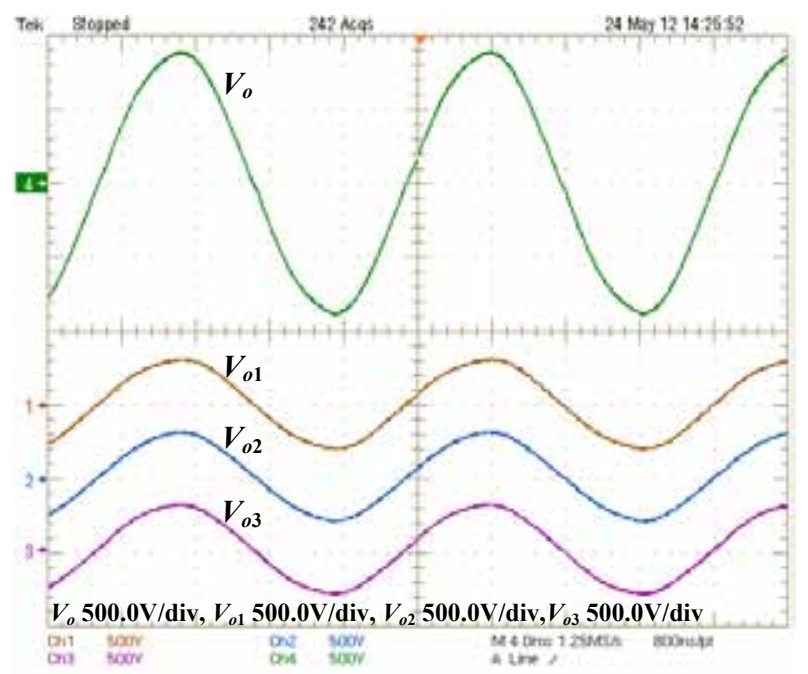

Fig. 9. Experimental results under resistive load operation. Outputvoltages of the UPS $\left(V_{o}\right)$, module $1\left(V_{o 1}\right)$, module $2\left(V_{o 2}\right)$ and module $3\left(V_{o 3}\right)$.

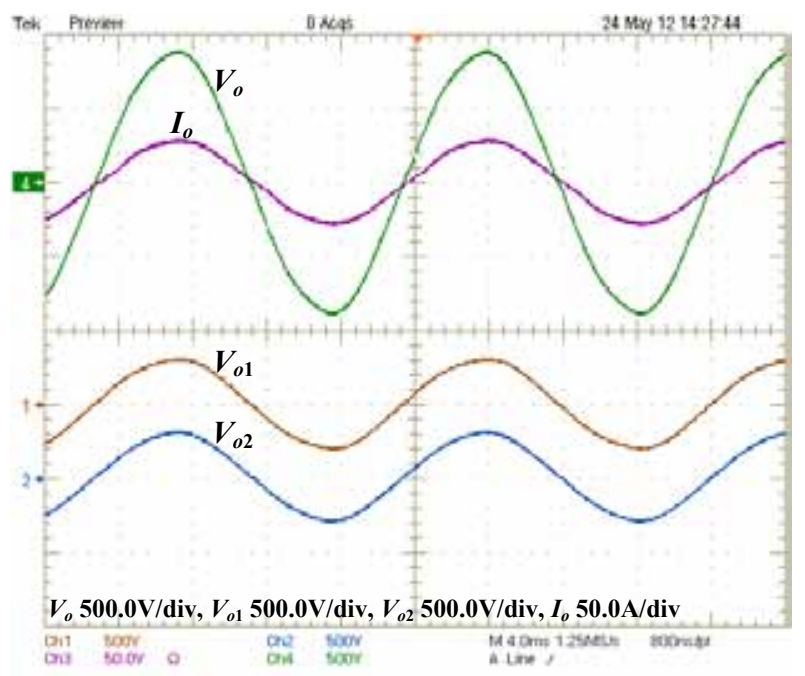

Fig. 10. Experimental results under resistive load operation. Outputvoltage of the UPS $\left(V_{o}\right)$, load current $\left(I_{o}\right)$ and output-voltages of module $1\left(V_{o 1}\right)$ and module $2\left(V_{o 2}\right)$.

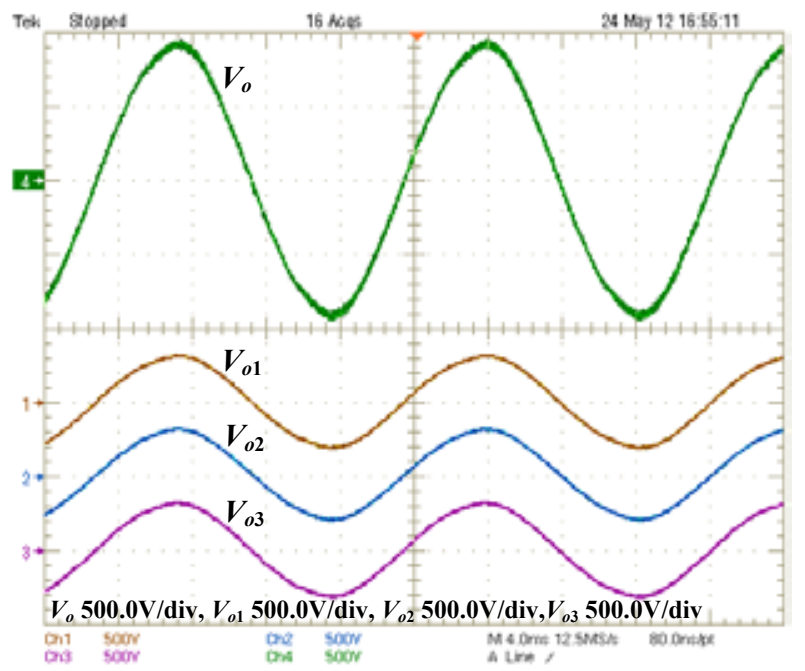

Fig. 11. Experimental results under inductive-load operation. Output-voltages of the UPS $\left(V_{o}\right)$, module $1\left(V_{o 1}\right)$, module $2\left(V_{o 2}\right)$ and module $3\left(V_{o 3}\right)$.

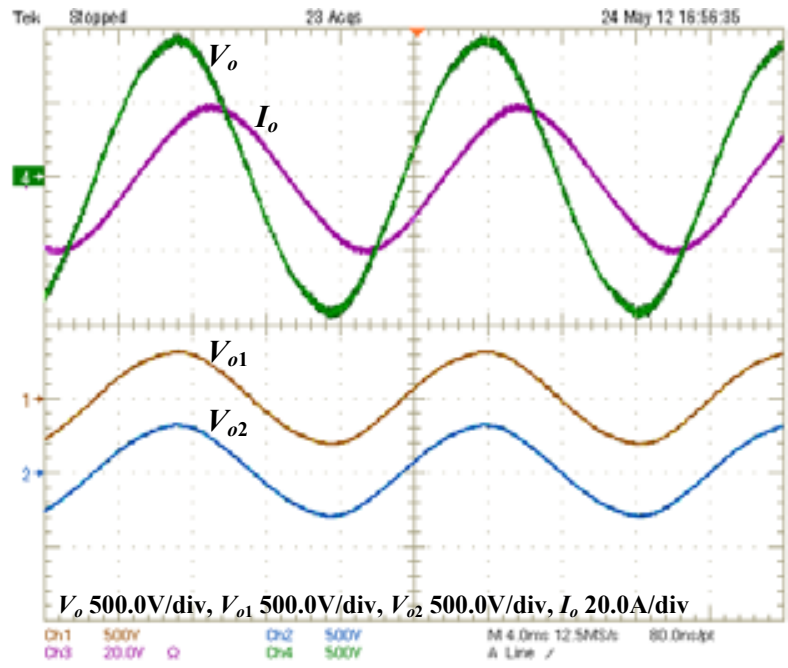

Fig. 12. Experimental results under inductive-load operation. Output-voltage of the UPS $\left(V_{o}\right)$, load current $\left(I_{o}\right)$ and outputvoltages of module $1\left(V_{o 1}\right)$ and module $2\left(V_{o 2}\right)$. 


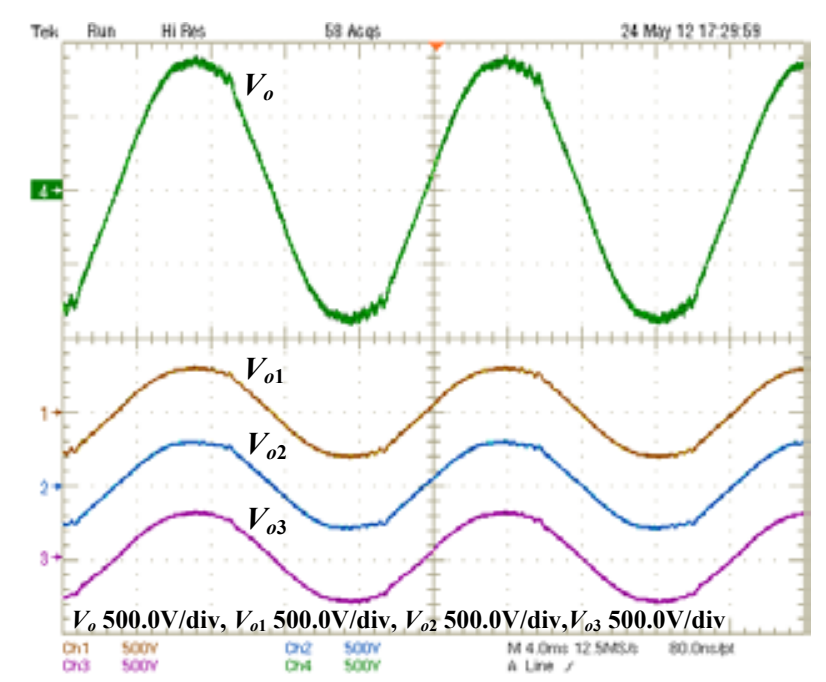

Fig. 13. Experimental results under non-linear load operation. Output-voltages of the UPS $\left(V_{o}\right)$, module $1\left(V_{o 1}\right)$, module $2\left(V_{o 2}\right)$ and module $3\left(V_{o 3}\right)$.

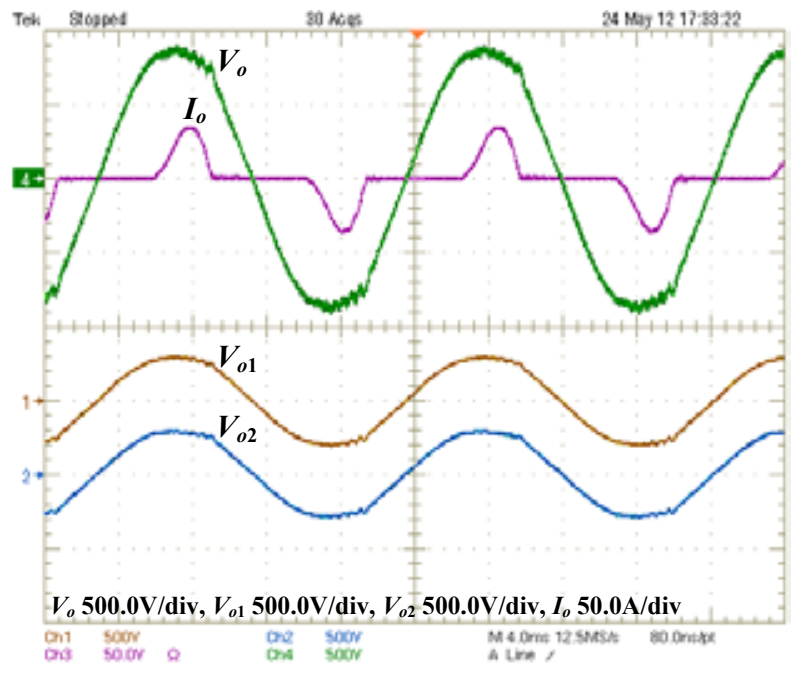

Fig. 14. Experimental results under non-linear load operation. Output-voltage of the UPS $\left(V_{o}\right)$, load current $\left(I_{o}\right)$ and outputvoltages of module $1\left(V_{o 1}\right)$ and module $2\left(V_{o 2}\right)$.

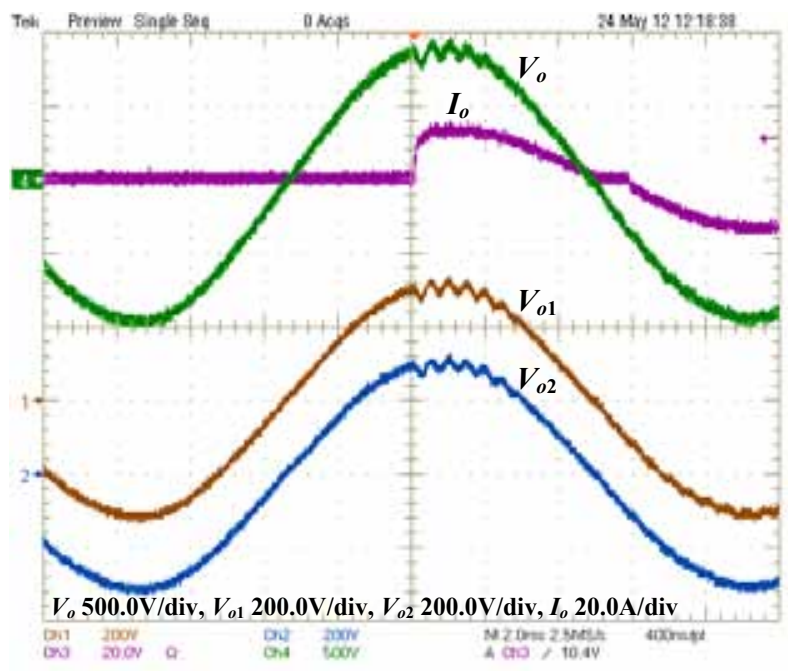

Fig. 15. Analysis of dynamic response of UPS during one resistive load step. Output-voltage of the UPS $\left(V_{o}\right)$, load current $\left(I_{o}\right)$ and output-voltages of modules $1\left(V_{o 1}\right)$ and module $2\left(V_{o 2}\right)$.

\section{REFERENCES}

[1] F. Blaabjerg, A. Consoli, J.A. Ferreira, J.D. van Wyk, "The Future of Electronic Power Processing and Conversion", IEEE Trans. Ind. Electron., vol. 41, no 1, pp. 3-8, Jan 2005.

[2] F. Blaabjerg, A. Consoli, J.A. Ferreira, J.D. van Wyk, "The Future of Electronic Power Processing and Conversion", IEEE Trans. Power Electron., vol. 20, no 3, pp. 715-720, May 2005.

[3] T. Fang, X. Ruan, C.K. Tse, "Control Strategy to Achieve Input Voltage Sharing and Output Voltage Sharing for Input-Series-Output-Series Connected Inverter Systems", IEEE Trans. Power Electron., vol. 25, no 6, pp. 1585-1596, Jun 2010.

[4] W. Chen, K. Zhuang and X. Ruan, “A Input-Series- and Output-Parallel-Connected Inverter System for HighInput-Voltage Applications", IEEE Trans. Power Electron., vol. 24, no 9, pp. 2127-2137, Sep 2009.

[5] T.B. Lazzarin, G.A.T. Bauer, I. Barbi, "A Control Strategy by Instantaneous Average Values for Parallel Operation of Single Phase Voltage Source Inverters Based on the Inductor Current Feedback", in Proc. of ECCE, pp. 495-502, 2009.

[6] T.B. Lazzarin, G.A.T. Bauer, I. Barbi, "A Control Strategy for Parallel Operation of Single Phase Voltage Source Inverters", in Proc. of IECON, pp. 25-30, 2009.

[7] J.F. Chen and C.L. Chu, "Combination VoltageControlled and Current-Controlled PWM Inverters for UPS Parallel Operation", IEEE Trans. Power Electron., vol. 10, pp. 547-558, Sep 1995.

[8] M. Pascual, G. Garcera, E. Figueres, F. GonzalezEspin, "Robust Model-Following Control of Parallel UPS Single-Phase Inverters", IEEE Trans. Ind. Electron., vol. 55, pp. 2870 - 2883, Aug 2008.

[9] U. Borup, F. Blaabjerg and P.N. Enjeti, "Sharing of Nonlinear Load in Parallel-Connected Three-Phase Converters", IEEE Trans. Ind. Electron., vol. 37, pp. 1817-1823, Nov/Dec 2001.

[10] J. C. Yeong and E. K. K Sng, "A Novel Communication Strategy for Decentralized Control of Paralleled Multi-inverter Systems", IEEE Trans. Power Electron., vol. 21, pp. 148 - 156, Jan 2006.

[11] J.M. Guerrero, L.G. de Vicuna, J. Matas, M. Castilla and J. Miret, "Output Impedance Design of ParallelConnected UPS Inverters With Wireless Load-Sharing Control", IEEE Trans. Ind. Electron., vol. 52, pp. 1126 - 1135, Aug 2005.

[12] K. De Brabandere, B. Bolsens, V. den Keybus, etc, “A Voltage and Frequency Droop Control Method for Parallel Inverters", IEEE Trans. Power Electron., vol. 22, pp.1107 - 1115, Jul 2007.

[13] T. T. Song, H. Chung and A. Ioinovici, "A HighVoltage DC-DC Converter with $V$ in $/ 3$-Voltage Stress on the Primary Switches", IEEE Trans. Power Electron., vol. 22, no 6, pp. 2124-2137, Jul 2007.

[14] D. V. Ghodke, K. Chatterjee and B. G. Fernandes, "Three-Phase Three Level, Soft Switched, Phase Shifted PWM DC-DC Converter for High Power 
Applications", IEEE Trans. Power Electron., vol. 23, no. 3, pp. 1214-1227, May 2008.

[15] W. Chen, X. Ruan, H. Yan, C.K. Tse, "DC/DC Conversion Systems Consisting of Multiple Converter Modules: Stability, Control and Experimental Verifications", IEEE Trans. Power Electron., vol. 24, no 6, pp. 1463-1474, Jun 2009.

[16] K. Siri, M. Willhoff and K. Conner, "Uniform Voltage Distribution Control for Series Connected DC-DC Converters", IEEE Trans. Power Electron., vol. 22, no 4, pp. 1269-1279, Jul 2007.

[17] R. Giri, R. Ayyanar and E. Ledezma, "Input-Series and Output-Series Connected Modular DC-DC Converters with Active Input Voltage and Output Voltage Sharing", in Proc. of IEEE APEC, pp. 1751-1756, 2004.

[18] J. W. Kimball, J. T. Mossoba and P. T. Krein, "A Stabilizing, High Performance Controller for Input Series-Output Parallel Converters", IEEE Trans. Power Electron., vol. 23, no. 3, pp. 1416-1427, May 2008.

[19] I.T. AG, "Eupec Modules Home Page", 26/05/2010, 2010; www.infineon.com.

[20] A. Nabae, I. Takahashi and A. Akagi, "A New NeutralPoint Clamped PWM Inverter”, IEEE Trans. Ind. Appl., vol. 19, no. 5, pp. 518-523, Sep./Oct 1981.

[21] L.G. Franquelo, J. Rodriguez, J. I. Leon and et al., "The Age of Multilevel Converters Arrives", IEEE Trans. Ind. Electron., vol. 2, n ${ }^{\circ}$ 2, pp. 28-39, Jun 2008.

[22] R. Hausmann, R. da Silva and I. Barbi, "Three-Phase NPC Inverter Using Three-Phase Coupled Inductor", in Proc. of IECON, vol. 1, pp. 913-918, 2009.

[23] G. Waltrich and I. Barbi, "The Three-Phase Cascaded Multilevel Inverter Using Power Cells With Two Inverter Legs in Series", IEEE Trans. Ind. Electron., vol. 57, no 8, pp. 2605-2612, Aug 2010.

[24] S. Sridharan and M. Mishra, "DC Capacitor Voltage Equalization in Neutral Clamped Inverters for DSTATCOM Application”, IEEE Trans. Ind. Electron., vol. 57, no 8, pp. 2768-2775, Aug 2010.
[25] C. Wang and Y. Li, "Analysis and Calculation of ZeroSequence Voltage Considering Neutral-Point Potential Balancing in Three-Level NPC Converters," IEEE Trans. Ind. Electron., vol. 57, no 7, pp. 2262 - 2271, Jul 2010.

[26] T.B. Lazzarin and I. Barbi, "High-output-voltage single-phase UPS based on series connection of lowoutput-voltage modular UPS," In Proc. of COBEP 2011, pp. 595-600, 2011.

[27] T.B. Lazzarin, "Paralelismo de Inversores de Tensão," Tese de Doutorado, UFSC, Florianópolis - SC, Brasil, 2010.

[28] R.F. Coelho, T.B. Lazzarin and D.C. Martins, "Modeling and control of the single-phase dc-ac PWM converter for grid-connected applications including a loop for average primary current controlling," In Proc. of COBEP 2011, pp. 334-340, 2011.

\section{BIOGRAPHIES}

Telles Brunelli Lazzarin was born in Criciúma, Santa Catarina, Brazil, in 1979. He received the B.S. degree in electrical engineering and the M.S. and Ph.D. degrees from the Federal University of Santa Catarina (UFSC), Florianópolis, Brazil, in 2004, 2006, and 2010, respectively.

$\mathrm{He}$ is currently a Professor in Federal Institute of Santa Catarina (IFSC). He is a member of the Brazilian Power Electronic (SOBRAEP) and a member of the IEEE Society.

Ivo Barbi was born in Gaspar, Santa Catarina, Brazil, in 1949. He received the B.S. and M.S. degrees in electrical engineering from the Federal University of Santa Catarina (UFSC), Florianópolis, Brazil, in 1973 and 1976, respectively, and the Dr.Ing. degree from the Institut National Polytechnique of Toulouse, Toulouse, France, in 1979.

He founded the Brazilian Power Electronics Society (SOBRAEP) and the Institute of Power Electronics (INEP), UFSC. He is currently a Professor with INEP and the Leader of the power electronics program of UFSC. 